\title{
A Decision-Making Model for Adopting Al-Generated News Articles: Preliminary Results
}

\author{
Soyoung Kim and Boyoung Kim *
}

Seoul Business School, Seoul School of Integrated Sciences and Technologies (aSSIST), Seoul 03767, Korea; soyoung_kim@stud.assist.ac.kr

* Correspondence: bykim2@assist.ac.kr

Received: 4 August 2020; Accepted: 7 September 2020; Published: 9 September 2020

\begin{abstract}
This study was conducted to present a consumer acceptance model for artificial intelligence (AI)-generated news articles in review of the most significant factors in the context of accepting AI-generated news articles. To this end, a survey was conducted regarding five key factors among individuals handling news production at media organizations who were familiar with AI-related news: benefits of technology utilization, recognized values, media reliability, content quality, and information perception. These factors were classified into 19 specific evaluation items in order to determine relative importance. According to the results of pairwise comparison analysis among elements through the analytic hierarchy process, hereunder referred to as AHP (analytic hierarchy process), it turned out that the importance of media reliability and content levels was relatively high, while the importance of recognized values and information perception was relatively low. It also turned out that among 19 specific items, the importance of institutional reliability, which was a subordinate item under media reliability, was of utmost value. Even if news articles were based on AI technology, their readers were more likely to be affected by reliability, which is a major attribute of journalism, than technical factors.
\end{abstract}

Keywords: artificial intelligence; AI-generated news; news article; media industry; AHP

\section{Introduction}

AI (artificial intelligence), which is a key element to the 4th Industrial Revolution, has started to affect the general media and journalism significantly under the name of "robot journalism" [1]. Robot journalism has been known to the general public since 2010 as a concept of generating news articles automatically by means of AI-based algorithms with no involvement of human journalist [2]. As AI extracts natural language phrases (NLP) from various data sets automatically, the traditional news industry has transformed [3]. When it comes to promptness and accuracy, which are regarded as critical in news articles, robot journalist now surpass human journalist.

Forbes, a U.S. Economist magazine, is the news agency that introduced AI-generated articles in 2012 for the first time. In 2013, the Associated Press introduced Wordsmith and promptly reported a large amount of data regarding the business performance of enterprises. The LA Times reported the earthquake situation real-time by utilizing "Quakebot". In 2016, the Washington Post started to adopt "Heliograf" in the Rio Olympic Games to report sports game results in a prompt and simple manner. In Korea, AI-generated news started to be used in 2015. In January 2016, the Financial News introduced IamFNBOT, an AI robot journalist. The Herald Business introduced HeRo, an AI robot journalist for English articles. eToday and Electronic Times utilized e2BOT and @NEWS respectively in their news article production. While these robot journalist handled existing news reports on corporate information and stocks, including current stock condition and fluctuation, corporate performance, etc., Yonhap News collected and analyzed data from every soccer game of the England Premier League and provided news reports by using SoccerBot. 
At present, robot journalism based on AI-generated news articles is expected to be established over the general media market [4]. As such, media agencies now introduce an AI-based news generation system as an efficient media management system [5]. As demands for AI-generated news among news consumers are increasing, the introduction and commercialization of AI-generated articles is recognized, no longer as a matter of choice, but a matter of eventuality.

In its initial stage, research on AI-generated articles or robot journalism in the media industry focused on the area of technology development. Specifically, the focus was on technology development and the issue of whether AI-generated articles could replace, and be as significant as, human-written articles. In this process, one of the main subjects of research was the dynamic conflict between robot journalist and human journalist [6]. Since AI-generated articles started to be commercialized, the scope of research has expanded to cover feedbacks from news consumers [2], ethics of algorithms, and legal issues such as article copyright $[7,8]$.

However, there has been little research on the market's perception of, or response to, AI, as well as on receptive attitudes in terms of news consumption or consumption values from the market's perspective while AI-generated articles are currently being commercialized. Also, in the news media environment with high technology and innovative businesses, the presses need the decision and creation of $\mathrm{Al}$-generated news articles to communicate with people under uncertainty and information asymmetry. Accordingly, this study defines determinant factors of the intention to accept AI-generated news articles and presents a model for the consumers' decision to accept AI-generated news by analyzing determinant factors affecting such acceptance attitudes most significantly. To this end, the analytic hierarchy process (AHP) methodology related to decision-making models was selected in a survey conducted on an expert group in the media industry in order to present a model consisting of objective factors of acceptance and strategic significances for the popularization of AI-generated news.

\section{Literature Review}

\subsection{Artificial Intelligence (AI) Technology and Journalism Change}

AI is based on the continuous development of computers, big data, and algorithms. While it has long been in its dark age, it is now advancing in various aspects, such as external cognition, logics, inference, prediction, etc., in the utilization of NLP deep-learning. As its business potentials are shown, investment in AI areas is increasing, particularly among global ICT enterprises [9]. In the face of significant changes over the global society, such as the 4th Industrial Revolution and COVID-19, AI applications including robots and untact technology are spreading rapidly. Against this background, robot journalism is likewise strengthening as AI technology is adopted in the media industry.

Traditionally, humans have been the main subject in journalism from coverage to reporting. In this area, which has been monopolized completely by humans, AI is now intervening and expanding its boundary [10]. Robot journalism has begun initially on the level of computer-assisted reporting (CAR), but at present, the trend is changing: robot journalism determines whether to produce certain news based on mathematical algorithms, with robots serving as inhuman agents practicing acts of article generation, which have been exercised by human journalist [11].

As shown in Table 1, the period of computer-assisted reporting has been followed by computational journalism on the basis of big data and network information. Coleman [12] defined computational journalism as "complementing tasks of journalism by combining knowledge from social science with algorithms and data". Computational journalism is used as a supplementary mechanism of the media in the process of searching for new information through the analysis of patterns hidden in data [4]. Since AI-based robot journalism has spread recently, however, articles have been prepared by AI in such ways as machine learning and deep learning. Furthermore, editing, distribution, and service are automated [13]. 
Table 1. Development steps of robot journalism.

\begin{tabular}{cccc}
\hline Classification & $\begin{array}{c}\text { Computer-Assisted } \\
\text { Reporting }\end{array}$ & Computational Journalism & $\begin{array}{c}\text { AI-Generated Robot } \\
\text { Journalism }\end{array}$ \\
\hline Background & $\begin{array}{c}\text { Emergence of } \\
\text { online news }\end{array}$ & $\begin{array}{c}\text { Spread of big data, } \\
\text { advancement of networking }\end{array}$ & $\begin{array}{c}\text { Machine-learning technology, } \\
\text { deep-learning technology }\end{array}$ \\
\hline AI algorithm & Low & Middle & High \\
\hline Human intervention & High & Middle & Low \\
\hline & Source: restructured by Baek (2018) [11] and Lee (2019) [14].
\end{tabular}

Accordingly, robot journalism is widely understood as a concept of generalizing a series of procedures and results for automated article preparation according to rules defined by AI algorithms with human intervention minimized [14]. In general, the process in which an AI algorithm generates a news article automatically is known to take the five following steps: (1) data crawling, (2) event extraction, (3) key event detection, (4) mood detection, and (5) news article generation [3]. In the case of AI-based robot journalist, it is possible to manage the distribution and advertisement of even customized articles based on customer information. Just like other industry sectors, the roles of traditional media organizations and journalists are affected by this changing paradigm in the field of the press [15].

Just as there have been various controversies on the evaluation of paintings by AI and human artists, there needs to be a discussion on a societal level now regarding the acceptance and values of articles generated by $\mathrm{AI}$ robots on the basis of big data and learning algorithms in comparison with articles written by humans on the basis of journalism and ideas [16]. Previous studies viewed robot-generated articles as more descriptive, informative, accurate, trustworthy, objective, and uninteresting than those written by humans. Meanwhile, articles written by human journalists were discerned to be coherent, well-written, clear, and pleasant to read $[17,18]$.

Some previous studies also pointed out that the accuracy and reliability of AI-generated news articles were doubted [19]. The main point of critics was that there is limitation in generating accurate and analytic articles since the intellectual level of robot journalist is inferior to that of humans [20]. However, AI algorithms are advancing gradually, and some with a positive view prospect that robot journalists will be able to enhance the accuracy of articles, judge values, and understand contexts based on a thorough analysis of big data, thus producing more creative news articles [21]. After all, technology continues to advance and the spread of robot journalism will require a new standard and evaluation on the part of the general public when it comes to the acceptance of news articles in the global society [22,23].

\subsection{Subsection}

Previous studies on the acceptance and selection of news articles applied evaluation standards of journalism based on political tendencies, social ideas, critical views, and values of contents $[24,25]$ or emphasized the reliability and inclination of entities producing news articles, such as journalists and media outlets [26,27]. In the case of AI-generated news articles, however, the receptive attitude towards technology and information, as well as the criteria of perception or appreciation of news content may affect the selection or acceptance of news articles. Thus, factors of news article selection need to be considered in a more complex perspective.

\subsubsection{Technology Using Benefits}

Basically, the acceptance of digital transformation, AI, and robotics in the 4th Industrial Revolution assumes the technology acceptance model (TAM) proven by Davis [28]. The TAM is viewed as a model with the most significant influence on studies of user behavior characteristics in the area of information technology (IT), which examines the intention of new technology adoption [29,30]. The TAM is a 
modified model [28] of the theory of reasoned action (TRA), appropriate for the context of new technology adoption. Proposed by Fishbein and Ajzen [31], the TRA is based on the assumption that an individual's intent of behavior is directly connected to actual behavior and is decided by one's attitude towards such behavior and relevant subjective norms. In contrast, the TAM emphasizes perceived usefulness and perceived ease of use based on the objectivity and attitude of behavioral intention. Among consumer acceptance studies on new technology-based media contents as well, the TAM was widely utilized either separately or in combination with another theory [32].

\subsubsection{Perceived Value}

The concept of "perceived values" became a major issue in the area of corporate strategies and marketing strategies aiming to improve customer values in the 1990s. Since then, marketing researchers have conducted studies for the explanation and analysis on customer behaviors [33-35] Perceived values are related not only to perceived quality or psychological states, but also to exchange of monetary sacrifices. In the context of service, quality is understood as a benefit and a consumed sacrifice for it on the part of customers. It affects a consumer's certain judgment or behavior intent [36]. The concept of perceived values is explained mainly in two perspectives: economic perspective and cognitive-emotional perspective. The economic perspective corresponds to effectiveness evaluation in relation to the comparison of cost and benefit. The cognitive-emotional perspective indicates evaluation in cognitive psychology regarding consumers' purchasing behaviors, as well as cognition and behavior characteristics in a certain emotional state. Whatever reason there may be to use media, recognizing the values is of importance. Value recognition can affect choices and use continuity [37]. From the users' perspective, in which useful information or joyful time is provided, value recognition affects the characteristics and use intentions of news articles [38,39].

\subsubsection{Media Credibility}

Reliability is defined as the probability of belief on a certain existence's intent at a certain time point. Reliability in certain information develops when the person perceives the appropriateness of the source of expertise, technology, and experience related to that information, as well as the objectivity and trustworthiness of the contents [40]. Previous studies from an information reliability perspective focused on two different aspects: professionalism and credibility [41]. With regard to news as well, usefulness or effectiveness assumes reliability from the consumers' perspective. Users would select certain news when they are certain about the reliability [42]. When it comes to the act of selecting news, the critical factor is the trust in the producer of articles, such as the media outlet and journalist [43]. The fact that reliability in news-generating entities counts in the process of article consumption is related to special attributes of the article production structure. Since news materials are processed as recognized by journalists, this process is viewed as an autonomous behavior of the news-producing subject $[44,45]$. News consumers expect that the reliability in a producing subject corresponds to that of the produced articles. When it comes to news articles, therefore, not merely the reliability of articles themselves but also the valuation of brands and the reliability of every individual involved in article production and distribution can affect article consumption directly [46].

\subsubsection{Content Quality}

"Content quality" means the quality of contents to be consumed. Content quality is acquired when an individual uses a service through a certain device or platform. Particularly, studies related to news contents have examined the relation between the quality of news contents and consumers' satisfaction with the news, the relation between motivation and use of news, and so forth [47-49]. According to previous studies, the quality of news contents affects the behavioral intention of users, and in the case of news services based on a new medium, such factors as variety, updatedness, professionalism, etc. affect users' intention, satisfaction, and use continuity. In addition, various factors of content quality evaluation have been introduced, including the timeliness, clarity, completeness, outward appearance, 
and understandability of news contents [50]. As news contents are digitalized, they are presented in various formats such as photos, texts, graphics, videos, etc. Accordingly, not only the quality of news contents but also various other factors related to visual expressions of contents, updatedness and genuineness of knowledge, social influence of contents, and reliability affect communication elements such as accuracy, understandability, and news acceptance [51,52].

\subsubsection{Information Awareness System}

Information is a variable since its meaning and value change depending on the living subject and external circumstances. It also can be interpreted differently in the context of users. Particularly in this digital era, participation through sharing and cooperation is more emphasized than accurate delivery when it comes to information [53]. Previous studies on information recognition and design were conducted for various purposes in different areas such as language, psychology, medical science, and design [54,55]. As ICT currently advances, computers, media, video devices, etc. collect, produce, process, preserve, deliver, and utilize information by means of software methods necessary to operate and manage information mechanisms. In this regard, there have been studies on user evaluation and attitudes towards information recognition and access systems [56]. In the case of interactive intellectual services, all information goes through the process of collection, interpretation, and inference. Throughout this process, differences in mutual communication with users, as well as information recognition and processing speed, can affect acceptance intention and satisfaction with services [57]. Since news is also digitalized in the media industry, users' information recognition and processing speed are likely to affect their news selection when the value of news increases as intangible information [58]. While users access information, grasp its flow, appreciate it, and absorb its context and meaning clearly, providing a systematic and highly approachable system becomes essential. The higher the ease of, and the keener the interest in, information access and processing through such an information recognition system are, the higher the likelihood of it affecting users' acceptance positively $[59,60]$.

\section{Research Methods}

\subsection{Analytic Hierarchy Process (AHP)}

The analytic hierarchy process (AHP) was originally developed by Professor Thomas Saaty at the University of Pennsylvania in the 1970s [61,62]. This is a decision-making methodology to detect the evaluator's knowledge, experience, and intuition by way of pairwise comparison between elements that form the decision-making hierarchy. The AHP is widely utilized in deriving key factors, setting policy alternatives, and establishing strategies $[63,64]$. The AHP features the theory's simplicity, easy application, and universal use. The AHP methodology derives the evaluation results based on the total ranks of relative importance among elements determined by each evaluator $[65,66]$. Accordingly, this study utilized the AHP in evaluating the relative importance of factors for the purpose of clarifying what affects the acceptance of AI-generated news articles significantly.

There are two basic approaches to AHP analysis [67]: The "geometric mean of pairwise comparison" determines the relative importance of each element based on the geometric average, whereas the "arithmetic mean of importance weight" determines importance by calculating the arithmetic average. This study adopted the geometric mean of pairwise comparison, which is widely used to analyze the relative importance of factors comprehensively. In consideration of the fact that the AHP, proposed by Yoo and Kim [68], is a probabilistic methodology to determine the difference between an input variable and a certain model output variable, this study determined the reliability of results, as well as the calculation basis of input variables, by setting their specific weights.

\subsection{Research Framework and Variables}

In reference to previous studies, particularly regarding the five major factors affecting news article users' behavioral intentions, this study selected the following key variables for decision-making on 
AI-generated news article acceptance: benefits of technology utilization, recognized values, media reliability, content quality, and information perception. As to definitions of each variable used in this study: (1) "Benefits of technology utilization" indicates attributes of usefulness and ease of news consumption while using innovative and new technology that can affect one's decision on AI-generated article acceptance. (2) "Perceived values" indicates the value attributes that stimulate individuals' will and motivation, affecting users' selection of AI-generated articles. (3) "Media reliability" indicates the extent of reliability of various elements related to article generation that affect users' selection of AI-generated articles. (4) "Content quality" indicates the level of article content quality that affects users' acceptance of AI-generated articles. (5) Finally, "information perception" indicates the ease or significance of an access process or system that affects users' acceptance of AI-generated articles (see Figure 1).

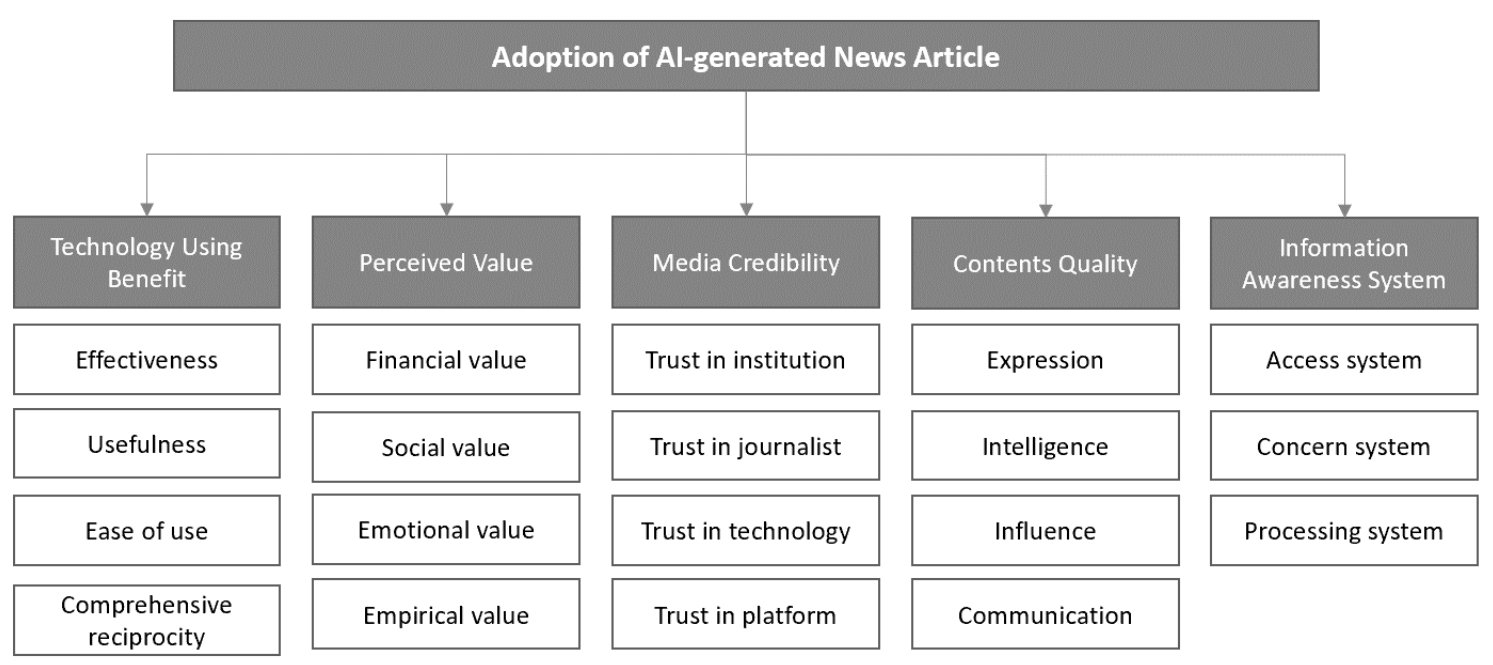

Figure 1. The research framework.

Under these five key variables, there were 23 subordinate factors (see Table 2). First of all, subordinate factors of benefits of technology utilization were, based on the previous studies of Davis et al. [27] and Adriani [31], the four following items: effectiveness, usefulness, ease of use, and comprehensive reciprocity. Those of perceived values were, based on the studies of Koritos et al. [35], Mazurek and Malagocka [38], the following: financial value, social value, emotional value, and empirical value. Those of media reliability were, based on the studies of Rimmer and Weaver [40], Usher [46], the following: trust in institution, trust in journalist, trust in technology, and trust in platform. Those of content quality were, based on the studies of DeLone and McLean [46], Allen et al. [52], the following: expression, intelligence, influence, and communication. Finally, those of information perception were, based on the studies of Duchastel [54] and Cui et al. [58], the three following items: access system, concern system, and processing system.

Table 2. Evaluation factors and definition.

\begin{tabular}{|c|c|c|c|}
\hline Evaluation Area & Evaluation Factors & Factor Definition & Related References \\
\hline \multirow{4}{*}{$\begin{array}{l}\text { Benefits of } \\
\text { technology utilization }\end{array}$} & Effectiveness & $\begin{array}{l}\text { Personal satisfaction and benefits } \\
\text { acquired from selecting } \\
\text { AI-generated articles }\end{array}$ & \multirow{4}{*}{ Davis et al. [28] Adriani [32] } \\
\hline & Usefulness & $\begin{array}{l}\text { Goal achievement and need fulfilled } \\
\text { from selecting AI-generated articles }\end{array}$ & \\
\hline & Ease of use & $\begin{array}{l}\text { Ease of use and functional } \\
\text { convenience acquired from selecting } \\
\text { AI-generated articles }\end{array}$ & \\
\hline & $\begin{array}{l}\text { Comprehensive } \\
\text { reciprocity }\end{array}$ & $\begin{array}{l}\text { Continued relations expected from } \\
\text { selecting AI-generated articles }\end{array}$ & \\
\hline
\end{tabular}


Table 2. Cont.

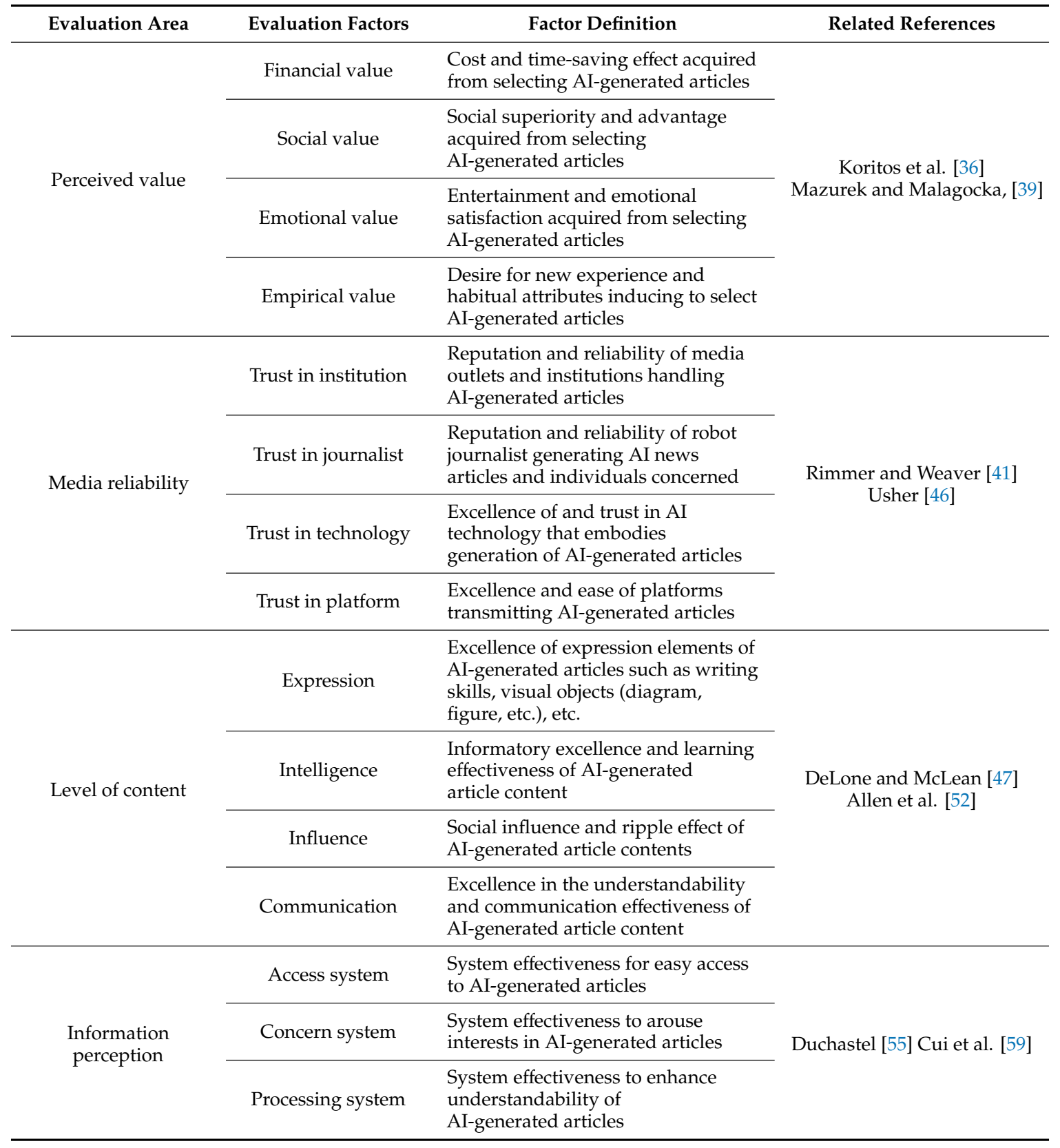

\subsection{Research Process and Data Collection}

This study presents an objective acceptance model based on factors affecting the acceptance of AI-generated news articles. To this end, a pairwise comparison questionnaire was utilized in the application of the AHP methodology and on the basis of the research framework shown in Figure 1. The questionnaire consisted of 38 questions in total, including 1 subjective question and 37 pairwise comparison questions. A pilot test was conducted among five administrators at a media outlet.

In order to secure study subjects' professionalism and high understanding of AI-generated news, the subject group included 15 journalists working at one of the six major media outlets of Korea introducing and utilizing AI-generated news articles and 15 engineers handling media technology. In consideration of the necessary knowledge and experience regarding AI-generated news, survey participants were selected from those with a field career of at least 5 years. The survey was conducted for 2 months from May to June 2020 by way of one-on-one personal interviews lasting about 30 minutes. 
As shown in Table 3, 90\% of the final data samples were male and $10 \%$ were female. A total of $26.6 \%$ were in their $30 \mathrm{~s}, 36.7 \%$ in their $40 \mathrm{~s}$, and $36.7 \%$ in their $50 \mathrm{~s}$. As for experience, $16.7 \%$ of the participants had had a career in the media industry for $5-10$ years, 30\% 10-20 years, and $53.3 \%$ more than 20 years. MS Excel program was used for data analysis. In order to secure the reliability of survey results, the consistency ratio (CR) of the comparing agents was checked and found to be under 1 , between 0.0015 and 0.0216 .

Table 3. Demographic information.

\begin{tabular}{cccc}
\hline & Characteristics & Frequency & Ratio (\%) \\
\hline \multirow{3}{*}{ Gender } & Male & 27 & 90 \\
& Female & 3 & 10 \\
& Total & 30 & 100 \\
\hline \multirow{2}{*}{ Age } & $30 \mathrm{~s}$ & 8 & 26.6 \\
& $40 \mathrm{~s}$ & 11 & 36.7 \\
& $50 \mathrm{~s}$ & 11 & 36.7 \\
Work Experience in the Media & Total & 30 & 100 \\
& 5-10 years & 5 & 16.7 \\
& $10-20$ years & 9 & 30 \\
& Over 20 years & 16 & 53.3 \\
& Total & 30 & 100 \\
\hline \multirow{2}{*}{ Professional Area } & Journalist Group & 15 & 50 \\
& Media Engineering Group & 15 & 50 \\
& Total & 30 & 100 \\
\hline
\end{tabular}

\section{Results}

\subsection{Comparison of Evaluation Variables}

As shown in Table 4, media reliability (0.373) was found to be the most significant factor among the five key factors. As for media articles, including AI-generated ones, it turned out that the basic reliability and content level of media articles affected the acceptance of AI-generated articles, rather than technical factors, in the following order: content level (0.197), benefits of technology utilization (0.184), perceived values (0.136), and information perception (0.110).

According to the analysis results of each area, it turned out that among the benefits of technology utilization factors, usefulness (0.364) and effectiveness (0.327) affected the decision of acceptance more significantly, and that among the perceived value factors, financial value (0.551) was of great importance, followed by empirical value (0.195) and then social value (0.157). The factor of the least effect turned out to be emotional value (0.098). Among media reliability factors, it turned out that trust in institution (0.385) was the most important factor affecting the decision of acceptance, and then trust in technology (0.286), trust in platform (0.205), and trust in journalist (0.123). As for the content level, the communication (0.333) was viewed as the most important factor of influence, followed by the intelligence (0.245), influence (0.233), and expression (0.190). Finally, among factors of information perception, system (0.424), processing system (0.356), and concern system $(0.219)$ were the important factors.

In the total list of 19 specific factors, those affecting acceptance of AI-generated news articles most significantly were trust in institution (0.144), trust in technology (0.107), and trust in platform (0.077), all of which turned out to be related to reliability. Another important factor next to them was financial value (0.075). The following factors also turned out to be important: usefulness (0.067), communication (0.065), effectiveness (0.060), intelligence (0.048), and access system (0.046).

\subsection{Comparison of Evaluation Areas between Journalist and Media Engineering Groups}

According to the comparative analysis of evaluation areas among journalist and media engineers, both groups viewed media reliability as the most important factor. While the group of journalists 
selected the level of content (0.250) and benefits of technology utilization (0.130), the group of media engineers selected the benefits of technology utilization (0.247) and perceived values (0.205) as important factors. This result shows that the difference between the two groups of the critical factors affecting Al-generated news articles (see Table 5).

Table 4. Weights and priority of evaluation variables.

\begin{tabular}{|c|c|c|c|c|c|c|}
\hline \multirow{2}{*}{ Evaluation Areas } & \multirow{2}{*}{$\begin{array}{c}\text { The Weights of Areas } \\
\text { Local }\end{array}$} & \multirow{2}{*}{ Evaluation Factors } & \multicolumn{4}{|c|}{ The Weights of Evaluation Factors } \\
\hline & & & Local & Priority & Global & Priority \\
\hline \multirow{4}{*}{$\begin{array}{c}\text { Benefits of } \\
\text { technology utilization }\end{array}$} & \multirow{4}{*}{0.184} & Effectiveness & 0.327 & 2 & 0.060 & 7 \\
\hline & & Usefulness & 0.364 & 1 & 0.067 & 5 \\
\hline & & Ease of use & 0.228 & 3 & 0.042 & 12 \\
\hline & & $\begin{array}{l}\text { Comprehensive } \\
\text { reciprocity }\end{array}$ & 0.081 & 4 & 0.015 & 18 \\
\hline \multirow{4}{*}{ Perceived value } & \multirow{4}{*}{0.136} & Financial value & 0.551 & 1 & 0.075 & 4 \\
\hline & & Social value & 0.157 & 3 & 0.021 & 17 \\
\hline & & Emotional value & 0.098 & 4 & 0.013 & 19 \\
\hline & & Empirical value & 0.195 & 2 & 0.027 & 15 \\
\hline \multirow{4}{*}{ Media reliability } & \multirow{4}{*}{0.373} & Trust in institution & 0.385 & 1 & 0.144 & 1 \\
\hline & & Trust in journalist & 0.123 & 4 & 0.046 & 10 \\
\hline & & Trust in technology & 0.286 & 2 & 0.107 & 2 \\
\hline & & Trust in platform & 0.205 & 3 & 0.077 & 3 \\
\hline \multirow{4}{*}{ Level of content } & \multirow{4}{*}{0.197} & Expression & 0.190 & 4 & 0.037 & 14 \\
\hline & & Intelligence & 0.245 & 2 & 0.048 & 8 \\
\hline & & Influence & 0.233 & 3 & 0.046 & 11 \\
\hline & & Communication & 0.333 & 1 & 0.065 & 6 \\
\hline \multirow{3}{*}{ Information perception } & \multirow{3}{*}{0.110} & Access system & 0.424 & 1 & 0.046 & 9 \\
\hline & & Concern system & 0.219 & 3 & 0.024 & 16 \\
\hline & & Processing system & 0.356 & 2 & 0.039 & 13 \\
\hline Total & 1.000 & & 5.000 & & 1.000 & \\
\hline
\end{tabular}

Table 5. Comparison analysis result on evaluation areas.

\begin{tabular}{ccccc}
\hline \multirow{2}{*}{ Evaluation Areas } & \multicolumn{4}{c}{ The Weights of Areas } \\
\cline { 2 - 5 } & Journalist Group & Media Engineering Group \\
\cline { 2 - 5 } & Local & Priority & Local & Priority \\
\hline Benefits of technology utilization & 0.130 & 3 & 0.247 & 2 \\
Perceived value & 0.086 & 5 & 0.205 & 3 \\
Media reliability & 0.416 & 1 & 0.309 & 1 \\
Level of contents & 0.250 & 2 & 0.138 & 4 \\
Information perception & 0.119 & 4 & 0.101 & 5 \\
Total & 1.0000 & & 1.0000 & \\
\hline
\end{tabular}

\subsection{Comparison of Evaluation Factors between Journalist and Media Engineering Groups}

As shown in Table 6, the result of the comparative analysis on each evaluation factor between the two groups indicates that both viewed trust in institution as the most important factor. In the comparison of the two groups based on the top five factors, it turned out that the journalist group recognized as most important in its acceptance of AI-generated news articles the following factors of reliability and article contents in order: trust in technology (0.116), communication (0.092), trust in platform (0.087), and intelligence (0.063). The media engineering group viewed the following factors in order as important: financial value (0.102), effectiveness (0.093), trust in technology (0.091), and usefulness (0.081). This result indicates the difference between the two groups, except in regards to the trust in technology factor. Particularly in the case of the media engineering group, it turned out that the two groups were keenly aware of the importance of the two following factors: benefits of technology utilization and financial value. 
Table 6. Comparison analysis result on evaluation factors.

\begin{tabular}{|c|c|c|c|c|c|c|}
\hline \multirow{3}{*}{ Evaluation Factors } & \multicolumn{4}{|c|}{ The Weights of Evaluation Factors } & \multirow{2}{*}{\multicolumn{2}{|c|}{ Priority of Factors (Global) }} \\
\hline & \multicolumn{2}{|r|}{ Local } & \multicolumn{2}{|r|}{ Global } & & \\
\hline & Journalist Group & Media Engineering Group & Journalist Group & Media Engineering Group & Journalist Group & Media Engineering Group \\
\hline Effectiveness & 0.279 & 0.378 & 0.036 & 0.093 & 13 & 3 \\
\hline Usefulness & 0.398 & 0.327 & 0.052 & 0.081 & 7 & 5 \\
\hline Ease of use & 0.251 & 0.203 & 0.033 & 0.050 & 14 & 7 \\
\hline Comprehensive reciprocity & 0.072 & 0.092 & 0.009 & 0.023 & 18 & 17 \\
\hline Financial value & 0.600 & 0.498 & 0.051 & 0.102 & 8 & 2 \\
\hline Social value & 0.125 & 0.193 & 0.011 & 0.040 & 17 & 12 \\
\hline Emotional value & 0.101 & 0.095 & 0.009 & 0.019 & 18 & 18 \\
\hline Empirical value & 0.174 & 0.214 & 0.015 & 0.044 & 16 & 9 \\
\hline Trust in institution & 0.387 & 0.382 & 0.161 & 0.118 & 1 & 1 \\
\hline Trust in journalist & 0.124 & 0.123 & 0.051 & 0.038 & 9 & 14 \\
\hline Trust in technology & 0.279 & 0.295 & 0.116 & 0.091 & 2 & 4 \\
\hline Trust in platforms & 0.211 & 0.200 & 0.087 & 0.062 & 4 & 6 \\
\hline Expression & 0.209 & 0.167 & 0.052 & 0.023 & 6 & 16 \\
\hline Intelligence & 0.253 & 0.231 & 0.063 & 0.032 & 5 & 15 \\
\hline Influence & 0.169 & 0.311 & 0.042 & 0.043 & 11 & 10 \\
\hline Communication & 0.369 & 0.291 & 0.092 & 0.040 & 3 & 11 \\
\hline Access system & 0.406 & 0.438 & 0.048 & 0.044 & 10 & 8 \\
\hline Concern system & 0.270 & 0.176 & 0.032 & 0.018 & 15 & 19 \\
\hline \multirow[t]{2}{*}{ Processing system } & 0.324 & 0.386 & 0.039 & 0.039 & 12 & 13 \\
\hline & 5.0000 & 5.0000 & 1.0000 & 1.0000 & & \\
\hline
\end{tabular}




\section{Discussion and Conclusions}

This study defined acceptance models based on important factors affecting acceptance of AI-generated news and comparatively examined the importance of these factors. The following are the analysis results: First, it turned out that in the evaluation of five key factors, media reliability was the factor affecting the acceptance of AI-generated news most significantly. This corresponds to previous studies $[69,70]$ where reliability was viewed as the most important element both in journalism and AI-generated news. As for AI-generated news articles, the accuracy of data and information is secured. However, there might be some differences even in the case of AI algorithms depending on the organization's learning method and scope, which indicates the limitation regarding complete reliance on the objectivity of intention in the process of generating news articles. Accordingly, although weather forecasts or articles of one-dimensional information may be more accurate and reliable, the reliability and objectivity of news articles are always an important factor in deciding whether they should be produced by humans or learned AI.

Second, among specific factors of media reliability, trust in institution turned out to be the most important factor. This suggests that the reliability of an institution, which manages AI and gives inputs to it can be a more sensitive factor rather than the reliability of robot journalists, AI technology, or relevant platforms. Previous studies likewise pointed out the significant relevance between news articles and the tendency or philosophy of media outlets [71-73]. After all, whether the journalist is a human or robot, the organization that supervises and decides news contents can affect robot journalism significantly.

Third, previous studies, in general, have suggested that the acceptance of technology-related products or services relies heavily on technological factors, such as ease and effectiveness [74,75]. In the case of news articles, however, the level of content is more significant than the benefits of technology acceptance according to the present study. Particularly, it turned out that rather than the expression and influence of articles, the level of expertise reflected in articles and their extent of communication were viewed as more important. In the case of AI-generated news articles, it is likely that in contrast with existing news articles, communication problems are due to the low level of knowledge or lack of communication skills on the part of robot journalist. This factor may induce rejection to AI news.

In view of practical significances based on the result above, media outlets need to emphasize organizational reliability in order to promote robot journalism and popularize AI-generated news articles. They need to put forth efforts to more actively share relevant information and promote the excellence and reliability of AI robot journalist generating news articles. In addition to that, efforts should continue to be put forth into sharing information transparently and promoting communication for the brand power and reliability of media outlets that the general public is aware of in consideration of the importance of reliability, not only on the part of robot journalist but also media outlets.

In terms of information perception, the importance of access systems has been emphasized more than that of interests in AI-generated news articles and relevant processing systems. Now it is time to emphasize the process of accessing AI-generated news articles. While AI-generated news is limited to mere objective facts, with the inclination of delivering information on weather, stock prices, sports game results, etc., it is likely that robot journalism will be popularized faster once attention is paid to the ease and variety of approaches to new areas of AI-generated news articles in the future, including society, politics, and economics.

Finally, research results show that in the context of acceptance of AI-generated news articles, reliability and level of contents are viewed as more important than benefits of technology and information perception. For this reason, media outlets need to consider establishing a complex system for both existing articles written by human journalists and AI-generated articles produced by robot journalists, rather than insisting on a company-wide press organization system on the basis of robot journalism in recognition of financial efficiency. While robot journalist involves geographical limits of coverage and interviews, human journalists need to focus on writing articles reflecting their insight on the actual context through comprehensive thinking by going around many different places and 
extending their networking of news sources. Humans and robots can complement each other efficiently while the former provide insight and the latter provide customized news services [31].

This study is of academic significance in that it defines factors related to the acceptance of AI-generated news and presents an acceptance model. At the same time, however, it involves limitations in model generalization since its subject group included only 30 related experts in Korea. At present, not only the current status of the media industry but also the level of robot journalism development and commercialization are different among countries. Thus, developmental research needs to be conducted among expert groups over this global society in order to develop an acceptance model that can be generalized properly. In addition, this study suggests a model by deriving factors of acceptance based on previous studies on general acceptance of technology and news articles. However, AI-generated news presents content with receptive and consumptive characteristics, unlike common products and services. There must be unique factors of acceptance or consumption value in AI-generated news articles. Accordingly, future studies need to clarify the differentiated factors of selection and stimulation regarding the acceptance of AI-generated news articles. Finally, this study suggests an acceptance model based on the opinions of an expert group, while an acceptance model needs to be developed in reflection of acceptance intention factors of the general public, the end users of articles. A future study needs to collect the opinions of general consumers on AI-generated news articles in such ways as managing big data from social network systems or collecting questionnaires from customers who have experienced Al-generated news articles to analyze them empirically.

Author Contributions: Funding acquisition, S.K.; methodology, B.K.; resources, S.K.; supervision, B.K.; writing-original draft, B.K. and S.K.; writing-review and editing, B.K. All authors have read and agreed to the published version of the manuscript.

Funding: This research received no external funding.

Acknowledgments: This research was supported by aSSIST (Seoul School of Integrated Sciences and Technologies).

Conflicts of Interest: The authors declare no conflict of interest.

\section{References}

1. Miller, T. Explanation in artificial intelligence: Insights from the social sciences. Artif. Intell. 2019, 267, 1-38. [CrossRef]

2. Clerwall, C. Enter the robot journalist. J. Pract. 2014, 8, 519-531. [CrossRef]

3. Dörr, K.N. Mapping the field of algorithmic journalism. Digit. J. 2015, 4, 700-722. [CrossRef]

4. Kim, D.; Kim, S. Newspaper companies' determinants in adopting robot journalism. Technol. Forecast. Soc. Chang. 2017, 117, 184-195. [CrossRef]

5. Cohen, S.; Hamilton, J.T.; Turner, F. Computational journalism. Commun. ACM 2011, 54, 66-71. [CrossRef]

6. Van Dalen, A. The algorithms behind the headlines. J. Pract. 2012, 6, 648-658. [CrossRef]

7. Li, Z. Artificial Intelligence pioneers predict ten major trends in the future of media. Sci. Technol. Daily 2016, 20, 58-59.

8. Chen, H. Application status and prospect of robot writing. Chin. Broadcast. 2019, 10, 62-65.

9. Carlson, M. The robotic reporter: Automated journalism and the redefinition of labor, compositional forms, and journalistic authority. Digit. J. 2015, 3, 416-431. [CrossRef]

10. Haim, M.; Graefe, A. Automated news better than expected? Digit. J. 2017, 5, 1044-1059. [CrossRef]

11. Lazer, D.; Baum, M.A.; Benkler, Y.; Berinsky, A.J.; Greenhill, K.M.; Menczer, F.; Metzger, M.J.; Nyhan, B.; Pennycook, G.; Rothschild, D.; et al. The science of fake news. Science 2018, 359, 1094-1096. [CrossRef] [PubMed]

12. Coleman, S. Believing the news: From sinking trust to atrophied efficacy. Eur. J. Commun. 2012, $27,35-45$. [CrossRef]

13. Striphas, T. Algorithmic culture. Eur. J. Cult. Stud. 2015, 18, 395-412. [CrossRef]

14. Tang, Q. Application and reflection of robot news. J. Res. News 2019, 10, 73-74.

15. Wang, Z. Opportunities and challenges of journalism and communication in the era of artificial intelligence. J. Zhejiang Inst. Med. Stud. 2018, 25, 12-16. 
16. Pennycook, G.; Rand, D.G. Lazy, not biased: Susceptibility to partisan fake news is better explained by lack of reasoning than by motivated reasoning. Cognition 2019, 188, 39-50. [CrossRef]

17. Chong, D.; Druckman, J.N. Counterframing effects. J. Politics 2013, 75, 1-16. [CrossRef]

18. Garret, R.K.; Long, J.; Jeong, M.S. New evidence on group polarization from partisan media to misperception: Affective polarization as mediator. J. Commun. 2019, 69, 490-517. [CrossRef]

19. Ho, J.H.; Lee, G.G.; Lu, M.T. Exploring the implementation of a legal AI bot for sustainable development in legal advisory institutions. Sustainability 2020, 12, 5991. [CrossRef]

20. Zhou, S. Preliminary exploration of the prospect of intelligent news writing. Wide Angle 2019, 9, 75-77.

21. Lee, J.H. A study on how reference groups, convenience and pursuit of information affect subscription-based webtoon service usage through reliability and curiosity. Converg. Soc. SMB 2017, 7, 101-109. [CrossRef]

22. He, A. Application of AI robots in news communication. Youth Rep. 2019, 12, 89-90.

23. Lim, J. The 4th industrial revolution and the emergence of algorithmic media: Changes in media form and cultural shock. New Phys. Sae Mulli 2017, 67, 530-541. [CrossRef]

24. Clerwall, S. From pink slips to pink slime: Transforming media labor in a digital age. Commun. Rev. 2015, 18, 98-122.

25. Anderson, C. Towards a sociology of computational and algorithmic journalism. New Media Soc. 2013, 15, 1005-1021. [CrossRef]

26. Young, M.L.; Hermida, A. From Mr. and Mrs. outlier to central tendencies: Computational journalism and crime reporting at the Los Angeles Times. Digit. J. 2015, 3, 381-397. [CrossRef]

27. Vosoughi, S.; Roy, D.; Aral, S. The spread of true and false news online. Science 2018, 359, $1146-1151$. [CrossRef]

28. Davis, F.D. Perceived Usefulness, Perceived Ease of Use, and User Acceptance of Information Technology. MIS Q. 1989, 13, 319-340. [CrossRef]

29. Liang, Z. Impact and reengineering of artificial intelligence technology on news production. N. Med. 2016, 9, 358-362.

30. Lee, H.; Oh, H. A Study on the deduction and diffusion of promising artificial intelligence technology for sustainable industrial development. Sustainability 2020, 12, 5609. [CrossRef]

31. Fishbein, M.; Ajzen, I. Belief, Attitude, Intention, and Behavior: An Introduction to Theory and Research; Addison-Wesley: Boston, MA, USA, 1975.

32. Roberto, A. The evolution of fake news and the abuse of emerging technologies. Eur. J. Soc. Sci. 2019, 2, 32-38.

33. Johnson, J.W.; Rapp, A. A more comprehensive understanding and measure of customer helping behavior. J. Bus. Res. 2010, 63, 787-792. [CrossRef]

34. Jeon, S.B.; Jeong, B.G.; Lee, J.S. The effect of relationship benefit on customer satisfaction and loyalty in the beauty salons. J. Soc. Cosmet. Sci. Korea 2013, 19, 252-263.

35. Gallarza, M.G.; Gil Saura, I. Value dimensions, perceived value, satisfaction and loyalty: An investigation of university students' travel behaviour. Tour. Manag. 2006, 27, 437-452. [CrossRef]

36. Koritos, C.; Koronios, K.; Stathakopoulos, V. Functional vs relational benefits: What matters most in affinity marketing? J. Serv. Mark. 2014, 28, 265-275. [CrossRef]

37. El-Haddadeh, R.; Osmani, M.; Thakker, D.; Weerakkody, V.; Kapoor, K. Examining citizens' perceived value of internet of things technologies in facilitating public sector services engagement. Gov. Inf. Q. 2019, 36, 310-320. [CrossRef]

38. Yu, J.; Lee, H.; Ha, I.; Zo, H. User acceptance of media tablets: An empirical examination of perceived value. Telemat. Inform. 2017, 34, 206-223. [CrossRef]

39. Mazurek, G.; Małagocka, K. Perception of privacy and data protection in the context of the development of artificial intelligence. J. Manag. Anal. 2019, 6, 344-364. [CrossRef]

40. Erdem, T.; Swait, J. Brand credibility, brand consideration, and choice. J. Consum. Res. 2004, 31, $191-198$. [CrossRef]

41. Lee, M.S. All roads lead to paltforms. KOCCA 2017, 22, 6-11.

42. Amazeen, M.A.; Muddiman, A. Saving media or trading on trust? Digit. J. 2018, 6, 176-195. [CrossRef]

43. Rimmer, T.; Weaver, D. Different questions, different answers? Media use and media credibility. J. Mass Commun. Q. 1987, 64, 28-44. [CrossRef] 
44. Mourão, R.R.; Thorson, E.; Chen, W.; Tham, S.M. Media repertoires and news trust during the early trump administration. J. Stud. 2018, 19, 1945-1956. [CrossRef]

45. Ognyanova, K. The social context of media trust: A network influence model. J. Commun. 2019, 69, 539-562. [CrossRef]

46. Usher, N. Re-thinking trust in the news. J. Stud. 2018, 19, 564-578. [CrossRef]

47. DeLone, W.A.; McLean, E.R. Information systems success: The quest for the dependent variable. J. Manag. Inf. Syst. 1992, 3, 60-95. [CrossRef]

48. Berry, L.L.; Parasuraman, A. Listening to the customer: The concept of a service-quality information system. Sloan Manag. Rev. 1997, 38, 65-76.

49. Delone, W.H.; McLean, E.R. The DeLone and McLean Model of Information Systems Success: A ten-year update. J. Manag. Inf. Syst. 2003, 19, 9-30. [CrossRef]

50. Chan, J.; Suen, W. A Spatial theory of news consumption and electoral competition. Rev. Econ. Stud. 2008, 75, 699-728. [CrossRef]

51. Chan-Olmsted, S.M.; Rim, H.; Zerba, A. Mobile news adoption among young adults. J. Mass Commun. Q. 2013, 90, 126-147. [CrossRef]

52. Allen, J.; Howland, B.; Mobius, M.; Rothschild, D.; Watts, D.J. Evaluating the fake news problem at the scale of the information ecosystem. Sci. Adv. 2020, 6, eaay3539. [CrossRef] [PubMed]

53. Nomura, T.; Suzuki, T.; Kanda, T.; Kato, K. Measurement of negative attitudes toward robots. Interact. Stud. 2006, 7, 437-454. [CrossRef]

54. Stein, E.W.; Zwass, V. Actualizing organizational memory with information systems. Inf. Syst. Res. 1995, 6, 85-117. [CrossRef]

55. Duchastel, P. Knowledge interfacing in cyberspace. Int. J. Ind. Ergon. 1998, 22, 267-274. [CrossRef]

56. Ash, J.S.; Berg, M.; Coiera, E. Some unintended consequences of information technology in health care: The nature of patient care information system-related errors. J. Am. Med. Inform. Assoc. 2004, 11, 104-112. [CrossRef]

57. Raj, J.S.; S, S. Virtual structure for sustainable wireless networks in cloud services and enterprise information system. J. ISMAC 2019, 1, 188-204. [CrossRef]

58. Brossard, D. New media landscapes and the science information consumer. Proc. Natl. Acad. Sci. USA 2013, 110, 14096-14101.

59. Cui, R.; Gallino, S.; Moreno, A.; Zhang, D.J. The operational value of social media information. Prod. Oper. Manag. 2018, 27, 1749-1769. [CrossRef]

60. Karimi, M.; Jannach, D.; Jugovac, M. News recommender systems-Survey and roads ahead. Inf. Process. Manag. 2018, 54, 1203-1227. [CrossRef]

61. Udo, G.G. Using analytic hierarchy process to analyze the information technology outsourcing decision. Ind. Manag. Data Syst. 2000, 100, 421-429. [CrossRef]

62. Ngai, E.W. Selection of web sites for online advertising using the AHP. Inf. Manag. 2003, 40, $233-242$. [CrossRef]

63. Wu, H.D. Systemic determinants of international news coverage: A comparison of 38 countries. J. Commun. 2000, 20, 110-130. [CrossRef]

64. Yang, C.; Huang, J.-B. A decision model for IS outsourcing. Int. J. Inf. Manag. 2000, 20, 225-239. [CrossRef]

65. Chan, A.H.; Kwok, W.; Duffy, V.G. Using AHP for determining priority in a safety management system. Ind. Manag. Data Syst. 2004, 104, 430-445. [CrossRef]

66. Hafeez, K.; Zhang, Y.; Malak, N. Determining key capabilities of a firm using analytic hierarchy process. Int. J. Prod. Econ. 2002, 76, 39-51. [CrossRef]

67. Salmeron, J.L.; Herrero, I. An AHP-based methodology to rank critical success factors of executive information systems. Comput. Stand. Interfaces 2005, 28, 1-12. [CrossRef]

68. Yoo, S.K.; Kim, B. The effective factors of cloud computing adoption success in organization. J. Asian Finance Econ. Bus. 2019, 6, 217-229. [CrossRef]

69. Chin, W.W.; Todd, P.A. On the use, usefulness, and ease of use of structural equation modeling in MIS Research: A note of caution. MIS Q. 1995, 19, 237-246. [CrossRef]

70. Diakopoulos, N. Algorithmic accountability. Digit. J. 2015, 3, 398-415. [CrossRef]

71. Gynnild, A. Journalism innovation leads to innovation journalism: The impact of computational exploration on changing mindsets. Journalism 2014, 15, 713-730. [CrossRef] 
72. Jung, J.; Song, H.; Kim, Y.; Im, H.; Oh, S. Intrusion of software robots into journalism: The public's and journalists' perceptions of news written by algorithms and human journalists. Comput. Hum. Behav. 2017, 71, 291-298. [CrossRef]

73. Zhou, M.; Zhao, L.; Kong, N.; Campy, K.S.; Qu, S.; Wang, S.; Timo, S.; Felix, P. The impact of artificial intelligence on individual performance: Exploring the fit between task, data, and technology. In Proceedings of the 28th European Conference on Information Systems (ECIS), Marrakech, Morocco, 15-17 June 2020; pp. 15-17.

74. Gottschalk, P.; Solli-Sæther, H. Critical success factors from IT outsourcing theories: An empirical study. Ind. Manag. Data Syst. 2005, 105, 685-702. [CrossRef]

75. Wong, K.K.K. Partial least squares structural equation modeling (PLS-SEM) techniques using Smart PLS. Market. Bull. 2013, 24,1-32.

(C) 2020 by the authors. Licensee MDPI, Basel, Switzerland. This article is an open access article distributed under the terms and conditions of the Creative Commons Attribution (CC BY) license (http://creativecommons.org/licenses/by/4.0/). 